\title{
PROFILE OF STUDENT PEDAGOGICAL CONTENT ABILITIES INTEGRATED FIELD INTRODUCTION PRACTICE STUDY PROGRAM OF PHYSICS EDUCATION
}

\author{
Muslimin $^{*}$ \\ Physics Education, University of Tadulako \\ e-mail: fisikamuslim@gmail.com
}

\begin{abstract}
This research aims to describe the profile of pedagogical knowledge (PK) capabilities, content knowledge $(C K)$, and pedagogical content knowledge (PCK) of physics students who are conducting integrated field recognition practices (PPLT). This research is qualitative descriptive research, where all data are collected based on facts obtained in the field, so descriptive data were obtained from respondents who were selected. The research subjects involved 6 physics education students who conducted PPLT at school as respondents. The selected category is based on a cumulative achievement index. The selected respondents were 2 high ability students, 2 medium students, and 2 low ability students. Data obtained through pedagogical knowledge observation sheets, content knowledge tests, and pedagogical content knowledge observation questionnaires. The data was taken from PPLT student learning compilation in schools. Based on the results of research on the ability of PK, CK, and PCK PPLT physics education students obtained, that students who have high PK and CK abilities have high PCK abilities, while students who have PK abilities and low CK abilities also have high PCK abilities.
\end{abstract}

Keyword: pedagogical knowledge, content knowledge, pedagogical content knowledge. 


\title{
PROFIL KEMAMPUAN PEDAGOGICAL CONTENT MAHASISWA PRAKTEK PENGENALAN LAPANGAN TERPADU PROGRAM STUDI PENDIDIKAN FISIKA
}

\author{
Muslimin ${ }^{*}$ \\ Pendidikan Fisika - Universitas Tadulako
}

\begin{abstract}
Abstrak
Penelitian ini bertujuan untuk mendeskripsikan profil kemampuan pengetahuan pedagogis (pedagogical knowledge/PK), konten pengetahuan (content knowledge/CK) dan pengetahuan konten pedagogis (pedagogical content knowledge/PCK) dari mahasiswa fisika yang sedang melakukan praktek pengenalan lapangan terpadu (PPLT). Penelitian ini merupakan penelitian deskriptif kualitatif, dimana semua data dikumpulkan berdasarkan fakta yang diperoleh di lapangan, sehingga data deskriptif didapat dari responden yang sudah dipilih. Subjek penelitian melibatkan 6 orang mahasiswa pendidikan fisika yang melakukan PPLT di sekolah sebagai responden. Kategori seleksi didasarkan pada indeks prestasi kumulatif. Responden terpilih adalah 2 mahasiswa berkemampuan tinggi, 2 mahasiswa sedang dan 2 mahasiswa berkemampuan rendah. Data diperoleh melalui lembar observasi pengetahuan pedagogis, tes pengetahuan konten, dan kuesioner observasi pengetahuan konten pedagogis. Data diambil dari kompilasi pembelajaran mahasiswa PPLT di sekolah. Berdasarkan hasil penelitian tentang kemampuan PK, CK, dan PCK PPLT mahasiswa pendidikan fisika diperoleh, bahwa mahasiswa yang memiliki kemampuan PK dan CK tinggi memiliki kemampuan PCK yang tinggi, sedangkan mahasiswa yang memiliki kemampuan PK dan kemampuan CK rendah ternyata juga memiliki kemampuan PCK yang tinggi.
\end{abstract}

Kata Kunci : pengetahuan pedagogis, konten pengetahuan, pengetahuan konten pedagogis.

\section{Pendahuluan}

Kemampuan content knowledge (CK) merupakan kemampuan pengetahuan yang harus dimiliki seseorang tentang materi pembelajaran yang harus dipelajari atau diajarkan. Pengetahuan mencakup tentang konsep, teori, gagasan, pengetahuan bukti serta praktek-praktek dan pendekatan untuk mengembangkan pengetahuan dan mengaplikasikan dalam kehidupan sehari-hari (Shulman, 1987).

Kemampuan pedagogical knowledge (PK), merupakan pengetahuan tentang teori kognitif, sosial, dan perkembangan belajar serta aktivitas siswa di dalam kelas. Koehler et al. (2014) menyatakan bahwa kemampuan PK merupakan kemampuan yang dimiliki guru untuk kepentingan berbagai pelaksanaan, strategi, dan metode dalam mendukung pembelajaran siswa. Guru seharusnya menguasai dan memahami secara mendalam terhadap pedagogik yang diperlukan siswa untuk mampu mengkonstruksi pengetahuan, sikap, dan keterampilan. Seorang guru harus memiliki pengetahuan yang memadai tentang cara mengajar, cara mentransfer pengetahuan berdasarkan tingkat kemampuan siswa dan menyadari tingkat pengetahuan siswa (Batur \& Balci, 2013).

Aspek yang harus dikuasai guru dalam proses pembelajaran yang berhubungan dengan pedagogical content knowledge (PCK) yaitu pengetahuan tentang strategi pembelajaran, pengetahuan materi, pengetahuan komunikasi dengan siswa dan pengetahuan penilaian dan evaluasi, pengetahuan tentang siswa dan karakteristiknya, pengetahuan tentang pengembangan kurikulum, serta pengetahuan tentang pengembangan potensi siswa (Usup Setiawan et al., 2018).

Kemampuan pedagogical content knowledge (PCK) merupakan sebuah kerangka konseptual yang harus dikuasai guru dalam proses pembelajaran yaitu konten, pedagogi dan konten PCK, agar kegiatan pembelajaran 
berjalan efektif dan efisien (Evi Suryawati, 2014).

Melalui proses pembelajaran guru harus mampu menyediakan situasi mengajar untuk membantu pembelajar dalam mengerti konten atas fakta ilmu pengetahuan (Putri Agustina, 2015). Kemampuan PCK merupakan kemampuan pengetahuan guru yang berhubungan dengan pedagogik, praktek pembelajaran, perencanaan pembelajaran, serta metode yang tepat untuk mengajarkan suatu materi. Oleh karena itu, keseimbangan dari pedagogical knowledge (PK) dan content knowledge (CK) akan sangat diperlukan dalam pemahaman tentang kemampuan PCK.

Shulman (1986) menyatakan perpaduan PK dan CK diperlukan dalam mengajar, juga diperlukan PCK yang bersumber dari guru untuk menciptakan pembelajaran yang bermanfaat bagi siswa, sedangkan Muhamad Imaduddin (2014) menyatakan bahwa guru harus memiliki pengetahuan khusus yang dimiliki oleh guru mengenai bagaimana mengajarkan konten tertentu kepada siswa dengan strategi yang mempu mengarahkan menuju pemahaman.

Kemampuan PCK guru merepresentasikan peleburan antara konten atau materi dan pedagogik dalam suatu pemahaman bagaimana topik-topik, masalah, atau isu-isu tertentu diatur, disajikan, dan diadaptasikan pada minat dan kemampuan peserta didik yang bervariasi serta disajikan dalam pembelajaran (Indrawati $\&$ Sutarto, 2016).

Kemampuan PCK guru merupakan kemampuan mengemas materi tertentu agar mudah diterima oleh siswa. Sholihah (2016) menjelaskan seorang guru apabila memiliki kemampuan PCK yang tinggi, maka guru tersebut memiliki kemampuan menyusun perangkat pembelajaran yang tinggi pula. Perangkat pembelajaran yang dipersiapkan guru sangat berperan langsung dalam kemampuan PCK, karena dapat mempengaruhi pendekatan dan metode pembelajaran di kelas. Guru yang profesional adalah guru yang mampu menciptakan lingkungan belajar yang menyenangkan, bukan hanya sekedar menguasai materi (Wati et al., 2018).

Untuk mencapai tujuan pembelajaran yang diharapkan, maka perpaduan antara CK, PK, dan PCK merupakan faktor yang sangat penting diperhatikan dalam proses pembelajaran. Kemampuan CK yang terdiri dari komponen konseptual, faktual, prosedural, dan metakognitif. Kemampuan PK yang terdiri dari komponen kemampuan performa siswa di kelas, strategi pembelajaran, metode dan teknik penilaian dalam pembelajaran, miskonsepsi dan kesulitan belajar siswa, kemampuan mengelola dan menguasai kelas, dan tindakan reflektif untuk peningkatan kualitas pembelajaran. Kemampuan CK dan PK akan dikaji hubungannya dengan kemampuan PCK dalam setiap komponen pada mahasiswa pendidikan fisika saat melakukan praktek pengenalan lapangan terpadu (PPLT). Praktek pengenalan lapangan terpadu merupakan uji coba kemampuan mahasiswa untuk mengajar pada sekolah menengah. Mahasiswa sebagai calon guru telah dibekali dengan kemampuan CK, PK, dan PCK melalui beberapa mata kuliah yang berhubungan dengan kemampuan sebagai calon guru. Mahasiswa yang melakukan PPLT perlu dianalisis kemampuannya dalam menerapkan ilmu yang telah dipelajari melalui perkuliahan.

\section{Bahan dan Metode}

Penelitian ini adalah penelitian deskriptif kualitatif, yaitu penelitian yang menggambarkan kemampuan PK, CK, dan PCK mahasiswa fisika yang melaksanakan praktek pengenalan lapangan terpadu (PPLT). Subjek dalam penelitian ini adalah mahasiswa pendidikan fisika yang melakukan PPLT di SMP Negeri dan MTs Negeri di Palu Barat pada tahun akademik 2019/2020 yang mengikuti pelaksanaan PPLT.

Responden dalam penelitian adalah mahasiswa pendidikan fisika yang melaksanakan PPLT. Subjek penelitian dipilih 6 orang sebagai responden berdasarkan kategori, yaitu 2 orang mahasiswa dalam kategori rendah, 2 orang dalam kategori sedang dan 2 orang mahasiswa dalam kategori tinggi. Kategori ini dipilih berdasarkan indeks prestasi kumulatif mahasiswa.

Jenis data dalam penelitian ini adalah data kualitatif yang diperoleh dari responden. Instrumen penelitian seperti pada Tabel 1. 
Tabel 1. Komponen dan indikator instrumen penelitian

\begin{tabular}{|c|c|c|}
\hline Komponen & Indikator & Jenis \\
\hline Tes PK & $\begin{array}{l}\text { 1. Memiliki pengetahuan dalam menilai kinerja siswa di kelas } \\
\text { 2. Menggunakan berbagai metode dan teknik penilaian } \\
\text { 3. Menerapkan berbagai strategi pembelajaran } \\
\text { 4. Miskonsepsi dan kesulitan belajar bagi siswa } \\
\text { 5. Mampu mengelola dan menguasai kelas dengan baik } \\
\text { 6. Tindakan reflektif untuk meningkatkan kualitas } \\
\text { pembelajaran }\end{array}$ & $\begin{array}{l}35 \text { soal } \\
\text { pilihan }\end{array}$ \\
\hline Tes CK & $\begin{array}{l}\text { 1. Kemampuan faktual } \\
\text { 2. Kemampuan konseptual } \\
\text { 3. Kemampuan prosedural } \\
\text { 4. Kemampuan metakognitif }\end{array}$ & 4 soal essay \\
\hline Tes PCK & $\begin{array}{l}\text { 1. Pengetahuan tentang strategi pembelajaran } \\
\text { 2. Pengetahuan tentang materi pembelajaran dan bahan } \\
\text { pembelajaran } \\
\text { 3. Komunikasi pengetahuan dengan siswa } \\
\text { 4. Penilaian dan evaluasi pengetahuan } \\
\text { 5. Pengetahuan tentang siswa dan karakteristik mereka } \\
\text { 6. Pengetahuan tentang pengembangan kurikulum } \\
\text { 7. Pengetahuan tentang pengembangan potensi siswa }\end{array}$ & $\begin{array}{l}\text { formulir } \\
\text { kuesioner }\end{array}$ \\
\hline
\end{tabular}

Kemampuan PK responden dianalisis dengan persentase rata-rata setiap indikator, kemampuan $\mathrm{CK}$ responden dianalisis melalui persentase rata-rata setiap indikator $\mathrm{CK}$, dan untuk kemampuan PCK dianalisis dengan persentase rata-rata setiap indikator kemampuan PCK. Selanjutnya persentase kemampuan yang diperoleh diberikan pengkategorian.

\section{Hasil dan Pembahasan}

Pengetahuan Pedagogis

Pengetahuan pedagogis (PK) fisika mahasiswa praktek pengenalan lapangan terpadu (PPLT) dianalisis berdasarkan masingmasing indikator. Data kemampuan PK mahasiswa fisika PPLT dapat dilihat pada Tabel 2. Berdasarkan Tabel 2, dapat diketahui tentang persentase rata-rata pada indikator PK yang berada pada kategori sedang. Hasil ini tentang PK mahasiswa yang melakukan praktik lapangan untuk mengajar di SMP Negeri dan MTs sebagai kandidat guru fisika, dapat menggunakan pengetahuan pedagogis dalam pembelajaran, terutama dalam mendukung penggunaan metode dan teknik penentuan yang bervariasi. Pengetahuan pedagogis digunakan juga untuk menghadapi kesulitan belajar bagi yang masih memiliki kesulitan dalam memperhatikan kesalah pahaman dan kesulitan belajar siswa. Selain itu juga untuk membahas hubungan antara kesesuaian materi dengan pemilihan strategi yang tepat dalam proses pembelajaran. Hal ini karena, sebelum pembelajaran terlebih dahulu telah mengoptimalkan strategi yang digunakan dalam proses pembelajaran sesuai rencana pembelajaran yang telah dirancang sebelumnya. Akan tetapi di kelas keperawatan hasilnya masih rendah, saat proses belajar mengajar hanya pada materi yang ada, sesuai dengan waktu yang tersedia, tanpa memperhatikan aktivitas siswa. Hasil ini bertentangan dengan hasil penelitian Sukaesih et al. (2017) yang dilakukan pada Guru Biologi yang melakukan microteaching mahasiswa jurusan Matematika dan Ilmu Pengetahuan Alam UNS yang memperoleh hasil $77 \%$ dari calon guru telah mengubah kesulitan dalam mengelola kelas secara efektif.

Pengetahuan Konten

Kemampuan kandidat terhadap pengetahuan konten (CK) untuk guru fisika 
Tabel 2. PK mahasiswa PPLT fisika untuk setiap indikator

\begin{tabular}{|c|c|c|c|}
\hline Kemampuan & Indikator Soal & $\begin{array}{c}\text { Rerata } \\
(\%)\end{array}$ & Kategori \\
\hline \multirow{6}{*}{$\begin{array}{l}\text { Pedagogical } \\
\text { Knowledge }\end{array}$} & $\begin{array}{l}\text { 1. Memiliki pengetahuan dalam melakukan } \\
\text { penilaian terhadap performa siswa di kelas }\end{array}$ & 56,0 & Sedang \\
\hline & $\begin{array}{l}\text { 2. Menggunakan metode dan teknik penilaian } \\
\text { yang bervariasi }\end{array}$ & 79,0 & Tinggi \\
\hline & $\begin{array}{l}\text { 3. Menerapkan strategi pembelajaran yang } \\
\text { bervariasi }\end{array}$ & 35,0 & $\begin{array}{l}\text { Sangat } \\
\text { rendah }\end{array}$ \\
\hline & $\begin{array}{l}\text { 4. Menyadari kemungkinan miskonsepsi dan } \\
\text { kesulitan belajar pada siswa }\end{array}$ & 37,0 & Rendah \\
\hline & $\begin{array}{l}\text { 5. Mampu mengelola dan menguasai kelas } \\
\text { dengan baik }\end{array}$ & 42,0 & Rendah \\
\hline & $\begin{array}{l}\text { 6. Melakukan tindakan reflektif untuk } \\
\text { peningkatan kualitas pembelajaran }\end{array}$ & 65,0 & Tinggi \\
\hline
\end{tabular}

Tabel 3 . CK mahasiswa PPLT fisika untuk setiap indikator

\begin{tabular}{llcc}
\hline Kemampuan & \multicolumn{1}{c}{ Indikator Soal } & $\begin{array}{c}\text { Rerata } \\
(\mathbf{\%})\end{array}$ & Kategori \\
\hline & 1. Kemampuan Faktual & 65,0 & Tinggi \\
Content & 2. Kemampuan Konseptual & 67,0 & Tinggi \\
Knowledge & 3. Kemampuan Procedural & 45,0 & Rendah \\
& 4. Kemampuan & 22,0 & Sangat rendah \\
\hline
\end{tabular}

yang diukur dengan bentuk hasil yang memenuhi empat dimensi pengetahuan adalah faktual, konseptual, prosedural, dan metakognitif. Tes ini dibuat dari dua jenis berdasarkan materi pelajaran yang disampaikan oleh calon guru fisika saat praktik mengajar. Kemampuan CK mahasiswa kandidat guru fisika dianalisis untuk setiap indikator. Data kemampuan CK untuk setiap indikator dapat dilihat pada Tabel 3.

Berdasarkan Tabel 3, dapat dilihat bahwa rerata keseluruhan kemampuan $\mathrm{CK}$ berada dalam kategori sedang, sebab sebaran kategori indikatornya dari sangat rendah, rendah, dan tinggi. Kemampuan tertinggi CK PPLT mahasiswa kandidat guru fisika adalah kemampuan faktual dan konseptual. Hal ini terjadi karena selama proses pembelajaran terkadang mahasiswa melakukan pembelajaran konseptual dengan menggunakan lingkungan sekolah sebagai media pembelajaran dan menggunakan animasi sebagai laboratorium virtual untuk menghubungkan antara teori dan kenyataan, sehingga mudah dijelaskan. Sejalan dengan hasil penelitian yang diperoleh Suryawati et al. (2014) yang dilakukan pada guru Biologi di SMA Negeri Pekanbaru, menunjukkan bahwa kemampuan menggunakan media komputer dapat meningkatkan kemampuan CK mahasiswa yang berada dalam kategori baik. Sedangkan kemampuan metakognisi masih rendah, karena responden yang mengajar di sekolah tempat penelitian, masih memiliki kemampuan akademik yang belum maksimal.

\section{Pengetahuan Konten Pedagogis}

Kemampuan pengetahuan konten pedagogis mahasiswa diukur menggunakan 38 item berbentuk kuesioner. Kemampuan PCK untuk setiap indikator dapat dilihat pada Tabel 4. Hasilnya menunjukkan bahwa persentase rerata secara keseluruhan untuk indikator PCK adalah 70,6\% dengan kategori tinggi. Indikator PCK tertinggi dalam pengetahuan komunikasi dengan siswa, terutama dalam sub-indikator, memberikan dan menjelaskan contoh yang mengandung konsep, yang diajarkan meng- 
Tabel 4. PCK mahasiswa PPLT fisika untuk setiap indikator

\begin{tabular}{|c|c|c|c|}
\hline Kemampuan & Indikator Pembelajaran & $\begin{array}{c}\text { Rerata } \\
(\%)\end{array}$ & Kategori \\
\hline \multirow{7}{*}{$\begin{array}{l}\text { Pedagogical } \\
\text { Content } \\
\text { Knowledge }\end{array}$} & $\begin{array}{l}\text { 1. Pengetahuan tentang strategi } \\
\text { pembelajaran }\end{array}$ & 70,7 & Tinggi \\
\hline & $\begin{array}{l}\text { 2. Pengetahuan materi pelajaran dan } \\
\text { pembelajaran yang mendidik }\end{array}$ & 71,2 & Tinggi \\
\hline & 3. Pengetahuan komunikasi dengan siswa & 74,3 & Tinggi \\
\hline & 4. Pengetahuan penilaian dan evaluasi & 64,2 & Tinggi \\
\hline & $\begin{array}{l}\text { 5. Pengetahuan tentang siswa dan } \\
\text { karakteristiknya }\end{array}$ & 68,0 & Tinggi \\
\hline & $\begin{array}{l}\text { 6. Pengetahuan tentang pengembangan } \\
\text { kurikulum }\end{array}$ & 74,3 & Tinggi \\
\hline & $\begin{array}{l}\text { 7. Pengetahuan tentang pengembangan } \\
\text { potensi siswa }\end{array}$ & 71,4 & Tinggi \\
\hline
\end{tabular}

gunakan bahasa tertulis. Dengan bantuan animasi sebagai laboratorium virtual yang baik dan benar serta menunjukkan sikap terbuka terhadap siswa dengan respons yang kategorinya tinggi. Selanjunya indikator PCK dengan persentase rata-rata terendah adalah kemampuan penilaian dan evaluasi $64,2 \%$, terutama yang terendah dalam sub-indikator, memberikan penjelasan tentang kesalahpahaman dan kesulitan serta kesalahan yang dibuat oleh siswa dalam menyelesaikan tugas atau pertanyaan yang diberikan oleh guru, baik langsung atau tidak langsung, memberikan penjelasan tertulis, menstabilkan jawaban yang tidak pasti, atau mengarahkan pendapat siswa ketika siswa mengerjakan tugas mereka dan memberikan penjelasan yang menguatkan untuk prosedur yang jelas.

Ketika jawaban dari siswa salah atau salah, responden tidak menjelaskan di mana siswa berada saat menjawab pertanyaan pada lembar kerja siswa. Beberapa responden masih tidak dapat mengarahkan pendapat siswa ketika siswa sedang mengerjakan tugas. Dari beberapa konsep yang dibahas dalam kelompok, hanya beberapa konsep yang diberikan penjelasan tentang penguatan oleh responden, meskipun konsep yang tidak dijelaskan lagi adalah salah satu poin dalam tujuan pembelajaran yang dirancang oleh responden. Hubungan antara kemampuan PK,
CK dan PCK calon siswa guru fisika dalam penelitian ini dapat dilihat pada Tabel 5 .

Hasil penelitian ini menjelaskan bahwa semua responden yang memiliki kemampuan tinggi, sedang dan rendah dengan kemampuan PK dan CK yang berbeda, cenderung tidak memiliki pengaruh dalam meningkatkan PCK, sebagaimana terlihat pada semua responden. Responden kedua menerima skor terendah untuk PK dan CK dan mengakibatkan PCK yang berada dalam kategori tinggi. Hal ini, karena kemampuan prosedur yang tinggi dan komponen metakognitif. Indikator pencapaian dua responden dalam menjawab tes kemampuan PK salah satunya adalah dengan menggunakan berbagai metode dan teknik penilaian serta mengambil tindakan reflektif terhadap kesulitan belajar siswa, sehingga siswa dapat melakukan komponen prosedur dan metakognitif walaupun komponen faktual dan konseptual juga berpengaruh.

Hasil wawancara dengan responden kedua, ternyata responden kedua telah memahami konsep perkembangan sosialemosional. Selain itu, juga telah dilakukan wawancara terkait dengan kemampuan CK responden dua, terutama pada konsep yang diajarkan, dimana responden mengerti konsep dengan menjawab benar dan memberikan alasan yang tepat selama wawancara. 
Tabel 5. Hubungan antara PK, CK dan PCK mahasiswa PPLT

\begin{tabular}{lcccc}
\hline No. & Nama & $\begin{array}{c}\text { Pedagogical } \\
\text { Knowledge (PK) }\end{array}$ & $\begin{array}{c}\text { Content } \\
\text { Knowledge }(\mathbf{C K})\end{array}$ & $\begin{array}{c}\text { Pedagogical Content } \\
\text { Knowledge }(\mathbf{P C K})\end{array}$ \\
\hline 1 & Responden 1 & 47 & 48 & 69 \\
2 & Responden 2 & 39 & 37 & 63 \\
3 & Responden 3 & 64 & 45 & 74 \\
4 & Responden 4 & 54 & 46 & 71 \\
5 & Responden 5 & 62 & 64 & 75 \\
6 & Responden 6 & 48 & 59 & 69 \\
\hline
\end{tabular}

Hasil analisis yang telah diuraikan menunjukkan bahwa indikator PCK yang dicapai adalah menjelaskan pentingnya memahami konsep materi dalam pendidikan atau dalam kehidupan nyata, memotivasi siswa untuk memahami konsep melakukan media virtual untuk mengarahkan pengetahuan tentang konsep, memilih dan menjelaskan komponen penting dan konsep yang mendasarinya. Dengan demikian mereka mudah dipahami oleh siswa, memodelkan konsep materi dalam bentuk media pembelajaran, alat bantu mengajar, menjelaskan materi secara sistematis, mengarahkan siswa untuk berpikir tentang konsep, memberikan motivasi kepada siswa. Sehingga timbal balik muncul dalam kegiatan belajar, memberi, dan menjelaskan contoh yang mengandung konsep yang tercerminkan ketika siswa mengalami kesalahpahaman dan kesulitan dalam memecahkan masalah yang dihadapi.

\section{Kesimpulan dan Saran}

Berdasarkan hasil penelitian tentang kemampuan PK, CK dan PCK pada pelaksanaan praktek pengenalan lapangan terpadu (PPLT) mahasiswa fisika, diperoleh bahwa mahasiswa yang memiliki kemampuan PK dan CK tinggi akan memiliki kemampuan PCK yang tinggi. Demikian juga terhadap mahasiswa yang memiliki kemampuan PK dan kemampuan CK rendah memiliki kemampuan PCK yang tinggi pula.

Penelitian tentang PCK dapat dilanjutkan dengan menambahkan variabel lain yang mempengaruhi kemampuan kognitif peserta PPLT, yang tidak dilakukan dalam penelitian ini. Dengan demikian akan diketahui variabel dominan yang paling mempengaruhi kemampuan kognitif peserta.

\section{Daftar Pustaka}

Adi P. M.J., Widodo, A., \& Sopandi, W. (2017). Science teachers' pedagogical content knowledge and integrated approach. IOP Conf. Series. Journal of Physics: Conf. Series 895.

Agustina, P. (2015). Pengembangan pedagogical content knowledge mahasiswa calon guru biologi FKIP Universitas Muhammadiyah Surakarta Melalui Simulasi Pembelajaran. Jurnal JPPI, 1(1), 1-15.

Depaepe, J.K. (2018). General pedagogical knowledge, self-efficacy and instructional practice: Disentangling their relationship in pre-service teacher education. Teaching and teacher Education, 69, 177- 190.

Eggen P., \& Kauchak, D. (2012). Strategi dan model pembelajaran mengajarkan konten dan keterampilan berpikir, Edisi keenam. Jakarta: PT. Indeks Permata Puri Media.

Evens M., Elen J., \& Depaepe, E. (2015). Developing pedagogical content knowledge. Developing lessons learned from intervention studies, Review Article Education Research International.

Garritz \& Andoni. (2010). Personal reflection: Pedagogical content knowledge and the affective domain of scholarship of teaching and learning. International Journal for the Scholarship of Teaching and Learning, 4(2).

Indrawati \& Sutarto. (2016). Studi pedagogical content knowledge mahasiswa calon guru fisika. Seminar Nasional Pendidikan, Peran pendidikan, sains, dan teknologi 
dalam membangun intelektual bangsa dan menjaga budaya nasional di era MEA.

Koehler, M.J., Mishra, P., Kereluik, K.T.S., Shin, \& Graham, C.R. (2014). The technological pedagogical content knowledge framework. InJ. M. Spector et al (Eds), Handbook of Research on Educational Communications and Technology. New York: Springer Science. pp. 101-111.

Imaduddin, M., Hidayah, F.F., \& Astuti, A.P. (2014). Deskripsi pedagogical content knowledge guru kimia menggunakan komponen model pentagon. Universitas Muhammadiyah Semarang. Jurnal Pendidikan Sains, 02.

Ozdemir, B.G., Sahin, O., Basibuyuk, K., Emrullah, E.E., \& Yasin, S.Y. (2017). Development of pedagogical content knowledge of classroom teachers on the numbers in terms of two components (IJRES). International Journal of Research in Education and Science, 3(2).

Rahmadhani, Y., Adi, R., \& Widi, P. (2016). Pedagogical content knowledge (PCK) guru dalam pembelajaran biologi SMA di kota Cimahi. Prosiding Seminar Nasional Sains dan Pendidikan Sains, 6, pp.17-24.

Setiawan, U., Maryani, E., \& Nandi. (2018). Pedagogical content knowledge (PCK) geography teacher high school. Journal of Scientific Social Sciences, 4(1), 12-21.

Sholihah, M., Lia Y., \& Wartono. (2016). Peranan TPACK terhadap kemampuan menyusun perangkat pembelajaran calon guru fisika dalam pembelajaran PostPack. Jurnal Pendidikan, EISSN: 2502471X. 1(2, 144-153.

Shulman, L.S. (1986). Those Who Understand: Knowledge growth in teaching. Educational Researcher, 15(2), 4-14.

Shulman, L.S. (1987). Knowledge and teaching: Foundations of the new reform. Harvard educational review, 57(1), 1-23.

Solihat, A.N., Suminawati, \& Afriza, E.F. (2019). Implementasi pedagogical content knowledge (PCK) dalam meningkatkan kemampuan kognitif siswa. Jurnal Ekonomi Pendidikan, 7(1), 69-76.

Sukaesih, S., Ridlo, S., \& Saptono, S. (2017). Profil kemampuan pedagogical content knowledge (PCK) calon guru biologi. Jurnal Lembaran Ilmu Kependidikan. 46(1).

Suryawati, E., Firdaus, L.N. \& Hernandez, Y. (2014). Analisis keterampilan technological pedagogical knowledge guru biologi SMA kota Pekanbaru. Jurnal Biogenesis, 11(1).

Wati, S., Fitriana, \& Mardiyana. (2018). Technological pedagogical content knowledge of junior high school mathematics teachers in teaching linear equation. IOP Conf. Series: Journal of Physics: Conf. Series. 1008012067.

Widodo, A. (2017). Teacher pedagogical content knowledge (PCK) and students' reasoning and wellbeing. IOP Conf. Series: Journal of Physics: Conf. Series 812. 